\title{
Potential therapeutic drugs for COVID-19 risk prolonging QT interval targeting hERG channel
}

\author{
Zequn Zheng ${ }^{1}$, Yujia WU ${ }^{1}$, Dingding QIAN², and Jiangfang LIAN $^{2}$ \\ ${ }^{1}$ Ningbo University \\ ${ }^{2}$ Li Huili Hospital
}

June 15, 2020

\begin{abstract}
The COVID-19 caused by SARS-CoV-2 poses a huge challenge to the medical system, especially the safe and effective COVID19 treatment methods, forcing people to look for drugs that may have therapeutic effects as soon as possible. Some old drugs have shown clinical benefits after a few small clinical trials attracting great attention. Clinically, however, many drugs including those currently shown to be effective against COVID-19 such as chloroquine, hydroxychloroquine, azithromycin and lopinavir/ritonavir may cause cardiotoxicity through acting on cardiac potassium channel, hERG channel due to their off-target effect. Blocking of hERG prolongs QT intervals on the electrocardiogram and thus might induce severe ventricular arrhythmias and even sudden cardiac death. Therefore, while focusing on the efficacy of COVID-19 drugs, the fact that they block hERG to cause arrhythmias can not be ignored. To develop safer and effective drugs, it is necessary to understand the interactions between drugs and hERG channels and the molecular mechanism behind this high affinity. In this review, we focus on the biochemical and molecular mechanistic aspects of related drug blockade in the hERG trying to provide insights into the QT interval prolongation caused by potential therapeutic drugs for COVID-19 and hope to weigh the risks and benefits when using related drugs.
\end{abstract}

\section{Keywords: COVID-19; drugs; hERG channel; QT interval; long QT syndrome (LQTS)}

Introduction

By the end of May 2020, in the six months since the end of 2019, the COVID-19 caused by SARS-CoV-2 swept the world, with more than 6 million infections and over 350,000 dead, making it the most terrifying killer of human life recently. The COVID-19 pandemic urgently requires effective and safe treatments that enable people to strive for rapid research and application of drugs, and at least 12 potential COVID-19 treatments are now being tested. This is a race against COVID-19(Kupferschmidt and Cohen 2020). However, although a series of drugs approved for other indications and a variety of research drugs are being studied in hundreds of clinical trials (available at ClinicalTrials.gov) around the world, there is currently no FDA approval of COVID-19 drugs(Jan et al. 2020, Panel. 2020). In the treatment guidelines issued on April 21, the National Institutes of Health (NIH) pointed out that at present, there are no drugs proven to be safe and effective in the treatment of COVID-19(Panel. 2020).

Early, some compounds have shown to be beneficial to patients after small clinical randomized trials, such as antimalarial drugs(Mercuroet al. 2020, Saleh et al. 2020, Wang et al. 2020, Yao et al. 2020), antiviral drugs(Cao et al. 2020a, Hunget al. 2020), and so on. However, the evidence of the effective treatment of these drugs is still insufficient, and part of them, such as chloroquine, due to the advocate of some public 
figures, may hinder the research of new potential therapeutic drugs(Ledford 2020). In addition, a noticeable problem is that these drugs may increase the risk of QT interval prolongation and ventricular arrhythmias(Giudicessiet al. 2020, Naksuk et al. 2020). A statement from the Canadian Cardiovascular Society (CCS) recommended that unnecessary drugs be discontinued, especially chloroquine, hydroxychloroquine, azithromycin, and lopinavir/ritonavir, and baseline electrocardiograms should be performed in high-risk patients(Sapp et al. 2020). In such cases, we have reviewed the QT prolongation reports of therapeutic drugs of COVID-19 and found that the use of drugs mentioned above alone or in combination has the risk of prolonging the QT interval, and even chloroquine and hydroxychloroquine have been listed as drugs that can cause direct myocardial toxicity. More importantly, patients with potential congenital arrhythmias, particularly long QT syndrome (LQTS), are at greater risk of fatal arrhythmias, such as Torsades de Pointes (TdP), during receiving the above drugs(Giudicessi et al. 2020, Kannankeril et al. 2010).

It is well known that many factors participate in prolonging QT interval, mainly divided into congenital LQTS (cLQTS) caused by genetic mutation and acquired LQTS (aLQTS) mainly due to the drug off-target effects, named as drug-induced LQTS (diLQTS), which can both cause TdP(Cubeddu 2016, Schwartz and Woosley 2016). Importantly, the hERG (Kv11.1) channel is the main target of drugs in diLQTS(Kannankerilet al. 2010, van Noord et al. 2010). Many drugs have been withdrawn from the clinic because of their severe potential arrhythmia targeting the hERG channel, including antibiotics, antivirals, antifungals, antimalarials, antidepressants, and so on(Cubeddu 2016, Mladěnka et al. 2018). The potential for hERG involvement in drug-associated arrhythmia is so strong that we need to pay more attention to the biological characteristics of hERG itself(Butleret al. 2019). Explaining and understanding the high affinity of drugs with the hERG channel requires revealing the molecular basis for hERG interactions with drugs to produce safer treatment drugs for diseases including COVID-19.

1. hERG channel

\section{The significance of the hERG channel}

hERG channel is also known as Kv11.1 channel or ERG1 potassium channel. hERG gene encodes the poreforming alpha subunit of a fast component of the delayed rectifier potassium channel $\left(\mathrm{I}_{\mathrm{Kr}}\right)$, which plays a fundamental role in the three-phase repolarization of the ventricular action potential, i.e., the repolarization of cardiac myocytes(Vandenberg et al. 2012). The dysfunction of hERG channel contributes to partial or complete reduction of $\mathrm{I}_{\mathrm{Kr}}$ current, resulting in prolonged action potential duration(Smith et al. 2016), manifested as a prolonged period of QT interval on electrocardiogram (ECG) (Figure1b), and if the extension exceeds the normal range (440 ms in men, $460 \mathrm{~ms}$ in women) becomes LQTS(Schwartz and Ackerman 2013, van Noord et al. 2010). Clinically, LQTS caused by hERG deficiency is called type 2 LQTS (LQT2), which is the second most common subtype of LQTS(Kapplinger et al. 2009).

The electrical activity of the heart is mediated by regulating the channels in which ions flow into and out of cardiomyocytes. Theoretically, the ion currents that constitute the ventricular action potential include inward and outward currents, and the balance of outward and inward current is the key to the formation of normal action potential duration. $\mathrm{Na}^{+}$and L-type $\mathrm{Ca}^{2+}$ currents $\left(\mathrm{I}_{\mathrm{Na}}\right.$ and $\mathrm{I}_{\mathrm{CaL}}$ ) are the most important inward currents in cardiomyocytes, and $\mathrm{k}^{+}$current $\left(\mathrm{I}_{\mathrm{K}}\right)$ is the major outward currents. Increased inward current or weakening of outward currents can result in a prolongation of action potential duration, leading to a prolonged QT interval (Figure1a)(van Noordet al. 2010). Excessive prolongation can facilitate the production of early after depolarization (EAD) in three-phase repolarization that will trigger TdP and even ventricular fibrillation if it reaches its threshold(Albert and Schuller 2014).

A decrease in outward potassium currents causing longer repolarization time due to the blocking of hERG, the effect of which is consistent with strengthening sodium or calcium currents. Therefore, the effect of drug inhibition on $\mathrm{hERG}$ channels appears to be corrected by drugs that block $\mathrm{I}_{\mathrm{Na}}$ and $\mathrm{I}_{\mathrm{CaL}}$. A classical example is amiodarone, a widely used class III antiarrhythmic drug, that shows an inhibition of multiple ion channels to balance the blocking of $\mathrm{I}_{\mathrm{Kr}}$, so it has rare malignant arrhythmia events generated by potassium channel blockage. However, cardiac and non-cardiac QT-prolonging drugs are often easy to target the hERG channel but not other ion channels to cause arrhythmias. Drugs with single ion channel effects and non-cardiac drugs 
that act on hERG are inevitably potentially arrhythmogenic. Given the importance of this matter, many studies have focused on revealing hERG biological characteristics to explain possible mechanisms of drug action and made some progress.

\section{hERG biogenesis and quality control}

hERG (ERG1) gene or KCNH2 is located on chromosome 7q35-36(Heet al. 2020, Vandenberg et al. 2012). There are at least three alternative KCNH2 transcription start site transcribed in the nucleus to produce mRNA, which encodes transcripts called KCNH2-1a, KCNH2-1b, and KCNH2-3.1, respectively. Nonsensemediated mRNA decay (NMD) maintains KCNH2 mRNA stability and protects cells from abnormal protein production through degradation of nonsense mutation possessing premature termination codons(Gong et al. 2007). Detected by NMD, qualified mRNA migrates to the ribosome for translation to generate the nascent polypeptide chain, and then undergoes core glycosylation (135KDa) in the endoplasmic reticulum (ER). The correctly folded peptide chain will enter the Golgi apparatus for further complex glycosylation (155KDa) (Figure2)(Foo et al. 2016, He et al. 2020, Nogawa and Kawai 2014).

The process of hERG protein biogenesis synthesis including folding, assembly, and translocation requires assistance from molecular chaperones, the most important of which is the heat shock protein (Hsp) family(Ficker et al. 2003, Iwai et al. 2013, Li et al. 2011, Zhang et al. 2014). Hsp70 and its homologous Hsc70 participate in the folding of nascent hERG and is believed that to modulate the hERG channel in a reciprocal way(Li et al. 2011, Zhang et al. 2014). Hsp70 suppresses hERG ubiquitination and increases hERG levels while Hsc70 reverses these effects (Li et al. 2011). Hsp90 reduces aggregation of misfolded protein and hERG ubiquitination by preventing interaction between endogenous C-terminus of Hsp70-interacting protein (CHIP) and hERG proteins(Ficker et al. 2003, Iwai et al. 2013). Specifically, Hsp40, as a co-chaperone for Hsp70, is thought to regulate hERG degradation(Walker et al. 2010). Type I Hsp40s, DNAJA1, and DNAJA2 can weaken the interaction between hERG and Hsc70 to promote the early degradation of hERG(Walker et al. 2010). Moreover, DNAJB12 and DNAJB14 also promote the tetramer assembly of hERG channel subunits through a mechanism independent of Hsp70 in the ER (Figure2)(Li et al.2017).

The mature protein will be transported to the plasma membrane to function. In reverse, if protein glycosylation cannot be done properly, the unqualified protein will retain in the ER or return to the ER from Golgi, and then up-regulate the levels of the ER molecular chaperone to cope with the condition. Nevertheless, if losing balances it will trigger ER stress coping responses, namely unfolded protein response (UPR) associated with the ubiquitin-proteasome system (UPS) for degradation, named ER-associated degradation (ERAD) (Figure2)(Wanget al. 2015). Another way of quality control is to rely on ubiquitination at the plasma membrane (PM) essential for cell homeostasis(Apaja and Lukacs 2014, Foo et al. 2016, Zhanget al. 2014). hERG protein on PM will internalize into clathrin-coated vesicles upon ubiquitination under the assistance of Caveolin (Cav), dynamin, and Arf6 (Zhang et al. 2014). Internalized proteins labeled by ubiquitin can be degraded by lysosomes or proteasomes, otherwise recycled back to the PM (Figure3)(Foo et al. 2016, Zhang et al. 2014). Many factors such as temperature, hypoxia, pH, potassium concentration, sex hormones, etc. can affect hERG protein maturation. Therefore, by altering the relevant factors that affect hERG maturation in the body, the drug can produce an effect of inhibiting or enhancing the function of hERG, which may further promote it to be the target of many drugs and also makes the regulation of hERG channel generation very complicated.

\section{hERG structure and gating kinetics}

hERG channel shares structural homology with other Kv channels(Whicher and MacKinnon 2016). The hERG channel act as a tetramer and four hERG subunits are arranged in a ring-shaped manner rather linearly arranged on the membrane(Vandenberg et al. 2012). Each subunit has six transmembrane fragments (S1 -S6), the N-terminal Per-Arnt-Sim (PAS) domain, and the C-terminal cyclic nucleotide-binding domain (cNBD) (Barros et al. 2020, Shi et al. 2020, Warmke and Ganetzky 1994). S1-S4 functions as a voltagesensing domain (VSD) and S4 provides the most important component of transmembrane voltage sensing with several positively charged residues(Barros et al. 2012). Two other transmembrane helices S5-S6 coupling 
with the intermediate pore loops of the four subunits constitutes the ion permeation pore-gate domain (PD) consisting of the permeation pathway, the potassium selectivity filter, and the channel gate (Figure4b)(Barros et al.2020, Wang et al. 2011). Importantly, N-terminal and C-terminal are respectively involved in the inactivation of the hERG channel (N-type inactivation and C-type inactivation)(Barros et al. 2012, Shi et al. 2020) and are also the binding sites of Hsp(Iwaiet al. 2013). Therefore, an interaction between hERG blocking drugs and Hsp may involve a change of gating kinetics.

Recently, the new hERG structure obtained from cryo-electron microscopy (cryo-EM) has aroused great attention, deleted most of the expected unstructured cytoplasmic regions $(\Delta 141-350$ at the N-terminal and $\Delta 871-1005$ at the C-terminal) (Figure4a)(Wang and MacKinnon 2017). The structure with a resolution of up to $3.8 \AA$ retains the gating properties similar to full-length channels because it does not change the major function of the hERG channel already recognized. It provides new insights into the molecular basis of high-affinity for hERG drugs block, the binding of hERG activators, and the molecular basis of hERG unique gating kinetics by demonstrating the important special structure of compounds binding(Butler et al. 2019, Vandenberg et al.2017).

Similar to other voltage-gated potassium channels, the hERG channel has three different conformational states, namely closed, open, and inactivated, respectively(Shi et al. 2020, Vandenberg et al. 2017, Vandenberg et al. 2012). However, hERG has its unique gating kinetics with slow activation and deactivation, but faster inactivation and recovery from inactivation, and these state changes depend on voltage changes(Shi et al. 2020, Vandenberg et al. 2017), leading to the inward rectifying characteristic(Smithet al. 1996, Spector et al. 1996). The altering rate of inactivation and deactivation reflects the potential potency of drug block.

In the early stage of the action potential, the hERG channel slowly opens, but rapidly inactivates. As depolarization voltage continues to decrease, hERG gradually recovers from inactivation(Witchel et al. 2001). Due to recovery from inactivation, hERG currents improve during repolarization followed by a much slower deactivation (Figure1c)(Barros et al. 2012, Vandenberg et al. 2017). Drugs can affect the opening and closing process of the channel, resulting in the activation curve shifts left or right and the tail current decay process becomes faster or slower. More recently, the selectivity filter at the hERG channel was reported as a pharmacological master mechanism to open potassium channels(Schewe et al. 2019). That offers a substantial boost in designing channel activators to rescue aLQTS or diLQTS. Because of the unique structure and gating kinetics of the hERG channel, in-depth understanding and research of molecular basis under different channel states will bring us help to develop safer drugs.

Pharmacology of hERG channel

As we all know, $\mathrm{I}_{\mathrm{Kr}}$ is the target of class III antiarrhythmic drugs like dofetilide, amiodarone, D-sotalol, etc. These drugs produce voltage- and dose-dependent hERG channel blockade. DiLQT results from off-target inhibition by a variety of compounds, most commonly because the drugs directly block the ion pathways(van Noordet al. 2010, Wang and MacKinnon 2017). In the past decades, considerable progress has been made in understanding the structural characteristics of drugs combined with hERG channels. The following insights were gradually formed: (i) Blockers gain access to a binding site that require the channel opening due to the drug binding located in the central cavity of the channel $\mathrm{PD}$ (Mitcheson et al. 2000, Vandenberg et al. 2012). (ii) Two key aromatic residues (Tyr652 And Phe656) on S6 are the most critical drug-binding sites(Butleret al. 2019) and blockers can be trapped in the inner vestibule by closing the activation gate once them inside the pore (Figure4c, Figure1d)(Tamargo et al. 2004). (iii) The cavity of the hERG channel is so large (the lack of Pro-X-Pro sequences in the S6) that it is sufficient to capture drugs at least as large as MK-499(Mitchesonet al. 2000, Tamargo et al. 2004). (iv) Most high-affinity drugs preferentially combine the inactivated state rather than the open state because mutations losing of inactivation reduce the affinity of some blockers, while mutations accelerating inactivation enhance the blocking potency(Perrin et al. 2008, Vandenberg et al.2017).

\subsection{Structural basis of drug binding}

Many studies have reported the importance of multiple aromatic residues for drug blockade based on the ho- 
mology difference between other $\mathrm{Kv}$ channels via the mutagenesis of individual residues in the S6 helix(Hanet al. 2015, Han et al. 2011, Jie et al. 2017, Rajamani et al. 2006, Sănchez-Chapula et al. 2003, Sánchez-Chapula et al. 2002, Takemasa et al. 2008). Among them, two aromatic residues of S6 Tyr652 and Phe656 is particularly significant. Their mutations can attenuate the drug blocking effect, confirming their high affinity for drug binding. It is believed that the Y652A and F656A mutations decrease the inhibitory effect by 17 times and 75 times, respectively(Helliwell et al. 2018). Chloroquine generates the effect of channel block can be restored by mutation of Tyr-652 showing that these key sites to block channels(Sánchez-Chapulaet al. 2002).

In addition to the two key residues mentioned above, other residues at the bottom of the pore helix, Thr623, Ser624, and Val625 and Phe557 on the S5 helix also contribute to drug binding, equally potent as Y652(Mitcheson et al. 2000, Saxena et al. 2016). The cryo-EM structure does not alter the basic feature of the hERG channel and retains all the functions essential for drug binding, which illustrates why these special amino acids of drug biding are so important(Wang and MacKinnon 2017). The positions of these amino acids in the sequence and molecular structure are highlighted and they are arranged on the surface of elongated, relatively hydrophobic pouches protruding from the central cavity(Wang and MacKinnon 2017). These pockets provide potential interaction sites for hERG blockers(Butler et al. 2019). To elucidate the chemical basis of drug binding, higher resolution structures will be needed and in combination with molecular dynamics simulations, it can accurately identify where and how drugs bind to the hERG channel, and why they bind differently to distinct conformation states of the channels.

\section{Disruption of hERG channel Trafficking}

As indicated earlier, the drugs binding into the pore region of the hERG channel exerts a direct blocking effect that disrupts the conduction of ions through the pore. Many different structurally drug groups cause QT prolongation targeting hERG through disrupting the trafficking of protein(Dennis et al. 2007, Kuryshev et al. 2005, Nogawa and Kawai 2014). These drugs include arsenic(Ficker et al. 2004), pentamidine(Kuryshev et al. 2005), fluconazole(Han et al.2011) and ketoconazole(Takemasa et al. 2008), fluoxetine(Hancox and Mitcheson 2006), cardiac glycosides(Wang et al. 2007), rosuvastatin(Feng et al. 2019), thioridazine(Liu et al.2020) and so on. Arsenic trioxide $\left(\mathrm{As}_{2} \mathrm{O}_{3}\right)$ is the first example of a drug that produces hERG liability by inhibition of channel protein trafficking through disrupting hERG-chaperone complexes(Ficker et al. 2004). Up to $40 \%$ of all hERG blockers exert combined hERG block and trafficking inhibition(Dennis et al. 2011). And as increasing drugs target the hERG channel, more drug studies have confirmed that the above two mechanisms can work together and probably are mediated by different mechanisms (Han et al. 2011, Hancox and Mitcheson 2006, Rajamani et al. 2006, Takemasa et al. 2008). It made the interfering effect of the hERG channel more complicated.

In general, numerous drugs reduce the generation of hERG mature 155-kDa form by disrupting the forward trafficking of hERG protein from ER to Golgi. This process is associated with molecular chaperones that help protein folding and assembling. For instance, inhibition of chaperone Hsp90 prevents maturation and promotes the proteasome degradation of hERG, thereby reducing the number of mature channels that can be integrated into the cell membrane(Cubeddu 2016). Different maturation of hERG can be estimated by comparing the expression levels of the two forms of this protein.

The mechanism of interference with hERG transport by drugs is similar to the class II mutation of LQT2 occurring due to congenital hERG mutation like A561V missense mutation, causing hERG channel trafficking defects(Delisle et al. 2004, Smith et al. 2016). For diLQTS and cLQTS, protein retention in the ER will induce high expression of molecular chaperones to promote protein maturation. Particularly, probucol reduces hERG expression from the cell membrane via accelerating Cav1 turnover(Figure3)(Guo et al. 2011, Guoet al. 2007). The antidepressant desipramine not only inhibits the forward transport of hERG but also increases channel endocytosis and ubiquitination degradation (Figure3)(Dennis et al. 2011). Notably, in the conditions of low extracellular potassium concentration, the caveolin-dependent internalization of hERG is also enhanced (Massaeli et al. 2010), which is attributed to the monoubiquitination of hERG at the membrane(Sun et al. 2011). There is currently no relevant evidence to support COVID-19 drugs that interfere with the maturation of hERG. The safe application of these drugs may require detailed information about 
hERG blocking intracellular mechanisms.

\section{Other mechanisms}

Another issue worth considering is that many drugs may alter drug metabolism which may further increase plasma levels of drugs that extend QT interval. Pharmacokinetic interactions usually involve agents metabolized by cytochrome P450 enzymes(van Noord et al. 2010). P450 (CYP) 3A is the highest expression subfamily, including isoforms CYP3A4, CYP3A5, CYP3A7, and CYP3A43(Eichelbaum and Burk 2001). CYP3A4 is the isoforms expressed in the liver and intestine(Eichelbaum and Burk 2001), which can oxidize a variety of drugs through many metabolic processes for detoxification(Dresser et al. 2000), and it is responsible for about $60 \%$ of the metabolism of currently known drugs(Feng et al. 2018, Zhou et al. 2005). Clinically important CYP3A4 inhibitors include antifungals (e.g. itraconazole and ketoconazole), macrolides (e.g. clarithromycin and erythromycin), antihypertensives (e.g. dihydralazine, verapamil, and diltiazem), anti-HIV drugs (e.g. ritonavir and delavirdine)(Dresser et al.2000, Zhou et al. 2005). These inhibitors can boost the plasma concentration of itself or other drugs that directly act on hERG and enhance cardiotoxicity(Feng et al. 2018, Zhi et al. 2015). In the list, ritonavir in lopinavir/ritonavir which has been shown to be effective for the treatment of COVID-19 as a strong CYP3A4 inhibitor can increase the oral bioavailability of certain HIV protease inhibitors, such as lopinavir(Dresser et al. 2000).

\section{Potential treatment for COVID-19}

According to the guidelines, there are no safe and effective drugs to kill SARS-CoV-2. The validity of the drugs currently in clinical use, including chloroquine, hydroxychloroquine, azithromycin, lopinavir/ritonavir, etc (Table1). are obtained from small clinical trials. Most of these studies have a relatively small sample size, and some of them have the opposite results. Therefore, when prescribing the drugs above, consider not only the results of the current trial but also the patient's condition, as well as possible serious adverse reactions and have careful assessment and choices until a comprehensive and reliable clinical trial is completed.

\subsection{Chloroquine and hydroxychloroquine}

Chloroquine (CQ) and hydroxychloroquine (HCQ) belong to quinoline antimalarial drugs, among which CQ is the most widely used antimalarial drug in history(Haeusler et al. 2018). In the treatment of COVID-19, CQ and HCQ have attracted a great deal of interest. An open-label, non-randomized study involving the application of HCQ (combined with azithromycin in some patients) shows that HCQ treatment is significantly associated with reduced/disappeared viral load in COVID-19 patients(Gautret et al. 2020). A small, prospective, observational study also suggests that CQ/CQ \pm azithromycin may be efficient on $\mathrm{SARS}-\mathrm{CoV}$ 2 , but the use of these drugs alone or in combination may prolong the QT interval, and therefore increase the incidence of $\mathrm{TdP}($ Saleh et al. 2020). In vitro study also found that $\mathrm{CQ}$ and HCQ are very effective in controlling SARS-CoV-2 infection(Wang et al. 2020), and HCQ is more effective than CQ in inhibiting SARS-CoV-2 in vitro(Yao et al. 2020).

There are now more than 100 clinical trials aimed at testing CQ or HCQ against COVID-19 and even CQ and HCQ have been used as standard treatments for COVID-19 patients in hospitals in some countries, such as China(Ledford 2020). Unfortunately, CQ hype is derailing the search for coronavirus treatments, even leading to the treatment available difficultly for patients with autoimmune diseases, which can result in potentially life-threatening manifestations, for instance, lupus nephritis(Jakhar and Kaur 2020, Ledford 2020, Yazdany and Kim 2020). Despite this situation, the data supporting the treatment of COVID-19 with CQ or HCQ is limited(Ledford 2020, Moore 2020, Yazdany and Kim 2020). In the treatment guidelines issued on April 21, the National Institutes of Health noted that there are insufficient data to recommend or oppose the use of CQ and HCQ for COVID-19 populations, and in COVID-19 patients receiving HCQ or azithromycin, 11\% -25\% of them have excessive QT prolonged to greater than 500 ms(Chorin et al. 2020, Panel. 2020). Therefore, better randomized controlled trials of CQ or HCQ are needed to effectively treat COVID-19(Ferner and Aronson 2020).

It is well known that antimalarial drugs have cardiotoxicity(White 2007), and QT prolongation is the most 
common adverse reaction(Llanos-Cuentas et al. 2014). Although small doses of CQ and HCQ are generally safe, both can block the Kv11.1 potassium channel(Giudicessi et al. 2020, Naksuk et al. 2020). Long-term use of CQ and HCQ has been reported to induce QT prolongation and malignant arrhythmia(Chen et al. 2006, Stas et al.2008), chloroquine-induced TdP in a COVID-19 patient also reported(Szekely et al. 2020). Antimalarial drug blocking hERG channel has also been found in heterologous expression models and animal models(Sánchez-Chapula et al. 2001, Traebert et al. 2004). In feline ventricular cardiomyocytes, CQ blocks several inward and outward membrane currents, and the order of potency is inwardly rectifying potassium current $\left(\mathrm{I}_{\mathrm{K} 1}\right)>\mathrm{I}_{\mathrm{Kr}}>\mathrm{I}_{\mathrm{Na}}>\mathrm{I}_{\mathrm{CaL}}$ (Sánchez-Chapula et al. 2001). Besides, CQ also slows the significant rate of hERG deactivation reflecting the dysfunction of drug-bound channels to close.(Sánchez-Chapula et al. 2002). On the contrary, as reported by hERG-lite(Wible et al. 2005), a novel systematical high-throughput screen for drug-induced hERG risk, CQ increases hERG transport(Borsini et al. 2012). The opposite result compared with the reduction of current indicates that there may be a complex mechanism under hERG inhibition induced by CQ. Besides, both CQ and HCQ are metabolized by CYP3A4, the risk of QT prolongation might increase if combined with CYP3A4 inhibitors such as ritonavir/lopinavir or azithromycin(Naksuk et al. 2020, Wuet al. 2020).

\subsection{Azithromycin}

Azithromycin, as a macrolide antibiotic, is thought to enhance the therapeutic effect of hydroxychloroquine in COVID-19(Gautret et al. 2020). Similarly, a combination of azithromycin and CQ/HCQ was shown to be helpful in the treatment of COVID-19, and there were no reports of death from fatal arrhythmic(Saleh et al. 2020). However, considering the cardiotoxicity of antimalarial drugs themselves, whether azithromycin when combined with them increases adverse reactions and whether we should use these drugs alone or in combination to treat COVID-19 is something worth noting. As previously mentioned in a cohort study, the effect of combined azithromycin on prolonging QT interval is more obvious(Mercuro et al. 2020), about one-quarter of the QT is prolonged excessively(Chorin et al. 2020). Perhaps the azithromycin itself does not usually cause a clinically significant prolongation of QT interval(Thomsen et al.2006), but its use in combination with CQ or HCQ may theoretically increase the risk of TdP(Juurlink 2020). These conflicting and poor-quality studies suggest that clinicians should carefully weigh risks and benefits and it may be advisable to avoid these drugs until there is more effective clinical and experimental evidence.

Azithromycin is considered to be the least likely to cause arrhythmia because of the least cardiotoxicity, with an estimated 47 added cardiovascular deaths per one million courses according to the report(Ray et al. 2012). Indeed, studies have confirmed that the rank order of arrhythmogenicity is estimated to be erythromycin > clarithromycin> roxithromycin > azithromycin(Milberg et al. 2002, Ohtani et al. 2000). Specially, azithromycin suppress $\mathrm{I}_{\mathrm{Kr}}$ current only under the condition of 50 times clinical related concentration (2075 $\mathrm{mg} / \mathrm{L}$ ), and the inhibition rate is about 30\%(Zhang et al. 2017). And so, not surprisingly, compared with dofetilide proved to be an hERG channel blocker, azithromycin has no same electrophysiological effects and thus azithromycin is said to be safe(Avedissian et al. 2019, Thomsen et al. 2006). However, based on the evidence of macrolides (such as erythromycin) targeting of hERG channels(Volberg et al. 2002), it is necessary to further investigate the interaction of azithromycin with hERG, even though azithromycin mainly increases cardiac $\mathrm{Na}^{+}$current while only slightly blocks $\mathrm{I}_{\mathrm{Kr}}$ (Yang et al. 2017). Moreover, azithromycin as a weaker CYP3A4 inhibitor than homologous antibiotics may increase the risk of QT prolongation when used in combination with antimalarial drugs in treating COVID-19(Wuet al. 2020). This seems to explain that azithromycin in combination with CQ or HCQ has a more significant QT prolongation effect.

\subsection{Lopinavir/ritonavir}

The HIV protease inhibitor class of antiretroviral drugs has obvious benefits for HIV. As an important CYP3A4 inhibitor, ritonavir can enhance the effect of other protease inhibitors such as lopinavir and atazanavir(Soliman et al. 2011, Zhou et al. 2005). The combined preparation lopinavir/ritonavir has aroused widespread interest after conducting a clinical trial for COVID-19(Cao et al. 2020a). The randomized trial found that for severe COVID-19 patients, lopinavir/ritonavir (400 mg and $100 \mathrm{mg}$, respectively) treatment does not significantly promote clinical improvement, reduce mortality or reduce the detectability of throat 
RNA of SARS-CoV-2, but it is beneficial for some secondary outcomes (e.g. a shorter time to stay in the intensive care unit (ICU)(Cao et al. 2020a, Stower 2020). Subsequently, although researchers advocated that lopinavir/ritonavir can be used as an alternative treatment guideline for COVID-19 before the completion of the World Health Organization SOLIDARITY trial(Cao et al. 2020b), the side effects including QT duration extension have raised concerns about the higher dose or longer treatment of this program. And based on the available evidence, it is uncertain whether lopinavir/ritonavir and other antiretroviral drugs can ameliorate clinical outcomes or prevent infection in patients with high-risk COVID-19(Ford et al. 2020). More recently it has been reported that triple combination of interferon beta-1b, lopinavir/ritonavir, and ribavirin are safer and superior to lopinavir / ritonavir alone in alleviating symptoms in patients with mild to moderate COVID-19(Hung et al. 2020). But the same question remains on how to balance the risks and benefits.

The evidence of the HIV protease inhibitor-induced arrhythmia is sufficient(Anson et al. 2005, Cao et al. 2020a, Gallagheret al. 2008, Han et al. 2015, Kikuchi et al. 2002, Soliman et al. 2011, Vicente et al. 2019). In vitro, lopinavir, nelfinavir, ritonavir, and saquinavir caused a dose-dependent hERG channel blockade(Anson et al. 2005). A randomized clinical trial showed that the treatment with ritonavir-enhanced protease inhibitors and non-enhanced regimens had similar effects on QT duration(Soliman et al. 2011), suggesting that combined treatment regimens may be more beneficial with fewer side effects, and for QT prolongation the role of the agent ritonavir as an enhancer might not be so important. Particularly, ritonavir $100 \mathrm{mg}$ does not cause QTc prolongation in healthy subjects(Sarapa et al. 2008), so it as a CYP3A4 inhibitor alone may only generate side effects when increasing the blood concentration of related drugs.

Except atazanavir, there is no relevant evidence to support whether other protease inhibitors affect hERG maturation and expression on the plasma membrane(Han et al. 2015). It has been confirmed that HIV protease inhibitors induce ERS in intestinal epithelial cells(Wuet al. 2010) and ERS can down-regulate cardiac ion channel expression(Liu et al. 2018). Referring to the effect of rosuvastatin on hERG(Feng et al. 2019), ERS may play an important role in diLQTS. Whether hERG is affected by ERS requires further verification.

\section{Future directions}

Various factors can affect the hERG channel to induce QT interval prolongation, and QT prolongation may also be the result of multiple ion channel actions. In the course of COVID-19, in addition to affecting the lungs, causing interstitial pneumonia and severe acute respiratory distress syndrome (ARDS), SARS-CoV-2 also damages multiple organs due to massive inflammatory factors, especially the cardiovascular system, leading to a variety of cardiac problems such as arrhythmia and myocarditis(Guzik et al. 2020, Inciardi et al. 2020, Zhenget al. 2020). In such cases, the cardiotoxicity of relevant therapeutic drugs may be obscured by the disease itself, so it is necessary to conduct comprehensive clinical management to consider whether to use these drugs, and if necessary, monitoring ECG is necessary. Most drug interaction with hERG channel induces a prolonging QT interval that is considered as a major risk factor in pharmaceutical drug development and in addition to hERG channels, drugs acting on many ion channels causing severe arrhythmias have become a limiting factor for their clinical use(Denning et al. 2016). Therefore, low cardiotoxicity might be a basic requirement before the drug enters clinical use, which requires a sensitive and effective experimental platform to carry out rigorous in vitro experiments, and it also requires tremendous effort for preclinical management.

In 2013, the U.S. Food and Drug Administration proposed an international initiative termed the Comprehensive In Vitro Arrhythmia Assay (CiPA), which recommends that multi-electrode array (MEA) can be used as a measurement tool, combined with human-induced pluripotent stem cell-derived cardiomyocytes (hiPSC -CMs) to conduct a preclinical assessment of the drug to evaluate the risk of TdP. The CiPA initiative requires a comprehensive ion current effect, not just $\mathrm{I}_{\mathrm{Kr}}$, to evaluate drug safety, and hiPSC-CMs will write a new chapter of safety assessment guidelines(Denning et al. 2016). Compared with heterologous system and animal models in research cLQTS or diLQTS, hiPSC-CMs as an autologous source of the reprogrammed cell shows a huge advantage. Although still immature(Veerman et al. 2015), they almost completely reproduce the phenotype of cardiomyocytes in vitro because they contain multiple ion channels that constitute the AP of cardiomyocytes(Ma et al. 2011). The results of hiPSC -CMs for proarrhythmia prediction under CiPA 
would serve as predictive indicators to the ion channel and in silico modeling prediction of proarrhythmic risk(Blinova et al. 2017). More importantly, individual-derived somatic cells with gene mutations can also be reprogrammed to differentiate into disease-specific cardiomyocytes, such as LQTS-hiPSC-CMs(Egashira et al. 2012, Itzhaki et al. 2011, Portero et al. 2017, Sala et al. 2019, Wuriyanghaiet al. 2018) and BrS-hiPSCCMs(Belbachir et al. 2019, Kosmidis et al. 2016), from LQTS and Brugada syndrome patients, respectively, which has a considerable significance for studying gene-drug interactions. MEA is a high-throughput screening tool for cellular electrical activity, whose measured field potential duration (FPD) reflects the QT interval and to some extent the activities of various ion channels(Nozaki et al. 2014).

Combined with hiPSC-CMs and MEA, many drugs can be screened sensitively and efficiently(Nozaki et al. 2014), with great potential and advantages in reducing the cost of drug development compared with the use of immortalized cell lines or animal models. Furthermore, disease-specific hiPSC-CMs can detect effective treatments in vitro that can perform effectively clinical translation(Mehta et al. 2018, Schwartz et al. 2019). In the future, related work should focus more on systemizing and standardizing hiPSC-CMs/MEA applications for comprehensive preclinical drug safety screening, and generating systematic, large-scale, and available drug safety data to further guide clinical practice. And for those drugs that must be used but have cardiotoxicity including QT prolongation, it is still necessary to further clarify the molecular mechanism behind to try possible rescue strategies. LUF7346 as an hERG channel allosteric modulators was recently shown that it can reverse congenital and drug-induced hERG channel blockade in hiPSC-CMs and heterologous expression models through binding to sites in the channel that are different from traditional drug binding sites to induce a conformational change in the channel(Salaet al. 2016). However, an excessively shortened QT interval caused by related rescue strategies is also a problem worthy of attention. The goal of precision medicine may be truly achieved through studies into clinical translation only after a comprehensive assessment of risks and benefits.

\section{References}

Albert RK \& Schuller JL (2014). Macrolide antibiotics and the risk of cardiac arrhythmias. American journal of respiratory and critical care medicine, 189(10): 1173-1180. doi: 10.1164/rccm.201402-0385CI.

Anson BD, Weaver JGR, Ackerman MJ, Akinsete O, Henry K, January CT, et al. (2005). Blockade of HERG channels by HIV protease inhibitors. Lancet (London, England), 365(9460): 682-686. doi: 10.1016/S01406736(05)17950-1.

Apaja PM \& Lukacs GL (2014). Protein homeostasis at the plasma membrane. Physiology (Bethesda), 29(4): 265-77. doi: 10.1152/physiol.00058.2013.

Avedissian SN, Rhodes NJ, Ng TMH, Rao AP \& Beringer PM (2019). The Potential for QT Interval Prolongation with Chronic Azithromycin Therapy in Adult Cystic Fibrosis Patients. Pharmacotherapy, 39(6): 718-723. doi: 10.1002/phar.2270.

Barros F, de la Peña P, Domínguez P, Sierra LM \& Pardo LA (2020). The EAG Voltage-Dependent K ${ }^{+}$ Channel Subfamily: Similarities and Differences in Structural Organization and Gating. Front Pharmacol, 11: 411. doi: 10.3389/fphar.2020.00411.

Barros F, Domínguez P \& de la Peña P (2012). Cytoplasmic domains and voltage-dependent potassium channel gating. Front Pharmacol, 3: 49. doi: 10.3389/fphar.2012.00049.

Belbachir N, Portero V, Al Sayed ZR, Gourraud JB, Dilasser F, Jesel L, et al. (2019). RRAD mutation causes electrical and cytoskeletal defects in cardiomyocytes derived from a familial case of Brugada syndrome. Eur Heart J, 40(37): 3081-3094. doi: 10.1093/eurheartj/ehz308.

Blinova K, Stohlman J, Vicente J, Chan D, Johannesen L, Hortigon-Vinagre MP, et al. (2017). Comprehensive Translational Assessment of Human-Induced Pluripotent Stem Cell Derived Cardiomyocytes for Evaluating 
Drug-Induced Arrhythmias. Toxicological sciences : an official journal of the Society of Toxicology, 155(1): 234-247. doi: 10.1093/toxsci/kfw200.

Borsini F, Crumb W, Pace S, Ubben D, Wible B, Yan GX, et al. (2012). In vitro cardiovascular effects of dihydroartemisin-piperaquine combination compared with other antimalarials. Antimicrob Agents Chemother, 56(6): 3261-70. doi: 10.1128/aac.05688-11.

Butler A, Helliwell MV, Zhang Y, Hancox JC \& Dempsey CE (2019). An Update on the Structure of hERG. Frontiers in pharmacology, 10: 1572. doi: 10.3389/fphar.2019.01572.

Cao B, Wang Y, Wen D, Liu W, Wang J, Fan G, et al. (2020a). A Trial of Lopinavir-Ritonavir in Adults Hospitalized with Severe Covid-19. N Engl J Med. doi: 10.1056/NEJMoa2001282.

Cao B, Zhang D \& Wang C (2020b). A Trial of Lopinavir-Ritonavir in Covid-19. Reply. N Engl J Med, 382(21). doi: 10.1056/NEJMc2008043.

Chen CY, Wang FL \& Lin CC (2006). Chronic hydroxychloroquine use associated with QT prolongation and refractory ventricular arrhythmia. Clin Toxicol (Phila), 44(2): 173-5. doi: 10.1080/15563650500514558.

Chorin E, Dai M, Shulman E, Wadhwani L, Bar-Cohen R, Barbhaiya C, et al. (2020). The QT interval in patients with COVID-19 treated with hydroxychloroquine and azithromycin. Nature Medicine. doi: 10.1038/s41591-020-0888-2.

Cubeddu LX (2016). Drug-induced Inhibition and Trafficking Disruption of ion Channels: Pathogenesis of QT Abnormalities and Drug-induced Fatal Arrhythmias. Current cardiology reviews, 12(2): 141-154. doi: $10.2174 / 1573403 \times 12666160301120217$

Delisle BP, Anson BD, Rajamani S \& January CTJCr (2004). Biology of cardiac arrhythmias: ion channel protein trafficking. 94(11): 1418-1428. doi: 10.1161/01.RES.0000128561.28701.ea.

Denning C, Borgdorff V, Crutchley J, Firth KS, George V, Kalra S, et al. (2016). Cardiomyocytes from human pluripotent stem cells: From laboratory curiosity to industrial biomedical platform. Biochim Biophys Acta, 1863(7 Pt B): 1728-48. doi: 10.1016/j.bbamcr.2015.10.014.

Dennis A, Wang L, Wan X \& Ficker E (2007). hERG channel trafficking: novel targets in drug-induced long QT syndrome. Biochemical Society transactions, 35(Pt 5): 1060-1063. doi: 10.1042/BST0351060.

Dennis AT, Nassal D, Deschenes I, Thomas D \& Ficker E (2011). Antidepressant-induced ubiquitination and degradation of the cardiac potassium channel hERG. J Biol Chem, 286(39): 34413-25. doi: 10.1074/jbc.M111.254367.

Dresser GK, Spence JD \& Bailey DG (2000). Pharmacokinetic-pharmacodynamic consequences and clinical relevance of cytochrome P450 3A4 inhibition. Clinical pharmacokinetics, 38(1): 41-57. doi: 10.2165/00003088200038010-00003.

Egashira T, Yuasa S, Suzuki T, Aizawa Y, Yamakawa H, Matsuhashi T, et al. (2012). Disease characterization using LQTS-specific induced pluripotent stem cells. Cardiovasc Res, 95(4): 419-29. doi: 10.1093/cvr/cvs206.

Eichelbaum M \& Burk O (2001). CYP3A genetics in drug metabolism. Nature medicine, 7(3): 285-287. doi: 10.1038/85417Dresser.

Feng P, Zhao L, Guo F, Zhang B, Fang L, Zhan G, et al. (2018). The enhancement of cardiotoxicity that results from inhibiton of CYP 3A4 activity and hERG channel by berberine in combination with statins. Chem Biol Interact, 293: 115-123. doi: 10.1016/j.cbi.2018.07.022.

Feng PF, Zhang B, Zhao L, Fang Q, Liu Y, Wang JN, et al. (2019). Intracellular Mechanism of RosuvastatinInduced Decrease in Mature hERG Protein Expression on Membrane. Mol Pharm, 16(4): 1477-1488. doi: 10.1021/acs.molpharmaceut.8b01102. 
Ferner RE \& Aronson JK (2020). Chloroquine and hydroxychloroquine in covid-19. BMJ (Clinical research ed.), 369: m1432. doi: 10.1136/bmj.m1432.

Ficker E, Dennis AT, Wang L \& Brown AM (2003). Role of the cytosolic chaperones Hsp70 and Hsp90 in maturation of the cardiac potassium channel HERG. Circ Res, 92(12): e87-100. doi: 10.1161/01.Res.0000079028.31393.15.

Ficker E, Kuryshev YA, Dennis AT, Obejero-Paz C, Wang L, Hawryluk P, et al. (2004). Mechanisms of arsenic-induced prolongation of cardiac repolarization. Molecular pharmacology, 66(1): 33-44. doi: 10.1124/mol.66.1.33.

Foo B, Williamson B, Young JC, Lukacs G \& Shrier A (2016). hERG quality control and the long QT syndrome. J Physiol, 594(9): 2469-81. doi: 10.1113/jp270531.

Ford N, Vitoria M, Rangaraj A, Norris SL, Calmy A \& Doherty M (2020). Systematic review of the efficacy and safety of antiretroviral drugs against SARS, MERS or COVID-19: initial assessment. Journal of the International AIDS Society, 23(4): e25489. doi: 10.1002/jia2.25489.

Gallagher DP, Kieran J, Sheehan G, Lambert J, Mahon N \& Mallon PW (2008). Ritonavir-boosted atazanavir, methadone, and ventricular tachycardia: 2 case reports. Clin Infect Dis, 47(3): e36-8. doi: 10.1086/589869.

Gautret P, Lagier J-C, Parola P, Hoang VT, Meddeb L, Mailhe M, et al. (2020). Hydroxychloroquine and azithromycin as a treatment of COVID-19: results of an open-label non-randomized clinical trial. International journal of antimicrobial agents: 105949. doi:10.1016/j.ijantimicag.2020.105949.

Giudicessi JR, Noseworthy PA, Friedman PA \& Ackerman MJ (2020). Urgent Guidance for Navigating and Circumventing the QTc-Prolonging and Torsadogenic Potential of Possible Pharmacotherapies for Coronavirus Disease 19 (COVID-19). Mayo Clinic proceedings. doi: 10.1016/j.mayocp.2020.03.024.

Gong Q, Zhang L, Vincent GM, Horne BD \& Zhou Z (2007). Nonsense mutations in hERG cause a decrease in mutant mRNA transcripts by nonsense-mediated mRNA decay in human long-QT syndrome. Circulation, 116(1): 17-24. doi: 10.1161/CIRCULATIONAHA.107.708818.

Guo J, Li X, Shallow H, Xu J, Yang T, Massaeli H, et al. (2011). Involvement of caveolin in probucolinduced reduction in hERG plasma-membrane expression. Molecular pharmacology, 79(5): 806-813. doi: 10.1124/mol.110.069419.

Guo J, Massaeli H, Li W, Xu J, Luo T, Shaw J, et al. (2007). Identification of IKr and its trafficking disruption induced by probucol in cultured neonatal rat cardiomyocytes. The Journal of pharmacology and experimental therapeutics, 321(3): 911-920. doi: 10.1124/jpet.107.120931.

Guzik TJ, Mohiddin SA, Dimarco A, Patel V, Savvatis K, Marelli-Berg FM, et al. (2020). COVID-19 and the cardiovascular system: implications for risk assessment, diagnosis, and treatment options. Cardiovascular research. doi: 10.1093/cvr/cvaa106.

Haeusler IL, Chan XHS, Guérin PJ \& White NJ (2018). The arrhythmogenic cardiotoxicity of the quinoline and structurally related antimalarial drugs: a systematic review. BMC Med, 16(1): 200. doi: 10.1186/s12916018-1188-2.

Han S-n, Sun X-y, Zhang Z \& Zhang L-r (2015). The protease inhibitor atazanavir blocks hERG K ${ }^{+}$channels expressed in HEK293 cells and obstructs hERG protein transport to cell membrane. Acta pharmacologica Sinica, 36(4): 454-462. doi: 10.1038/aps.2014.165.

Han S, Zhang Y, Chen Q, Duan Y, Zheng T, Hu X, et al. (2011). Fluconazole inhibits hERG K(+) channel by direct block and disruption of protein trafficking. European journal of pharmacology, 650(1): 138-144. doi:10.1016/j.ejphar.2010.10.010.

Hancox JC \& Mitcheson JS (2006). Combined hERG channel inhibition and disruption of trafficking in drug-induced long QT syndrome by fluoxetine: a case-study in cardiac safety pharmacology. British journal 
of pharmacology, 149(5): 457-459. doi: 10.1038/sj.bjp.0706890.

He S, Moutaoufik MT, Islam S, Persad A, Wu A, Aly KA, et al. (2020). HERG channel and cancer: A mechanistic review of carcinogenic processes and therapeutic potential. Biochimica et biophysica acta. Reviews on cancer, 1873(2): 188355. doi: 10.1016/j.bbcan.2020.188355.

Helliwell MV, Zhang Y, El Harchi A, Du C, Hancox JC \& Dempsey CE (2018). Structural implications of hERG K channel block by a high-affinity minimally structured blocker. The Journal of biological chemistry, 293(18): 7040-7057. doi: 10.1074/jbc.RA117.000363.

Hung IF, Lung KC, Tso EY, Liu R, Chung TW, Chu MY, et al. (2020). Triple combination of interferon beta-1b, lopinavir-ritonavir, and ribavirin in the treatment of patients admitted to hospital with COVID-19: an open-label, randomised, phase 2 trial. Lancet. doi: 10.1016/s0140-6736(20)31042-4.

Inciardi RM, Lupi L, Zaccone G, Italia L, Raffo M, Tomasoni D, et al. (2020). Cardiac Involvement in a Patient With Coronavirus Disease 2019 (COVID-19). JAMA cardiology. doi: 10.1001/jamacardio.2020.1096.

Itzhaki I, Maizels L, Huber I, Zwi-Dantsis L, Caspi O, Winterstern A, et al. (2011). Modelling the long QT syndrome with induced pluripotent stem cells. Nature, 471(7337): 225-9. doi: 10.1038/nature09747.

Iwai C, Li P, Kurata Y, Hoshikawa Y, Morikawa K, Maharani N, et al. (2013). Hsp90 prevents interaction between CHIP and HERG proteins to facilitate maturation of wild-type and mutant HERG proteins. Cardiovasc Res, 100(3): 520-8. doi: 10.1093/cvr/cvt200.

Jakhar D \& Kaur I (2020). Potential of chloroquine and hydroxychloroquine to treat COVID-19 causes fears of shortages among people with systemic lupus erythematosus. Nat Med. doi: 10.1038/s41591-020-0853-0.

Jan H, Faisal S, Khan A, Khan S, Usman H, Liaqat R, et al. (2020). COVID-19: Review of Epidemiology and Potential Treatments Against 2019 Novel Coronavirus. Discoveries (Craiova, Romania), 8(2): e108. doi: 10.15190/d.2020.5.

Jie L-J, Wu W-Y, Li G, Xiao G-S, Zhang S, Li G-R, et al. (2017). Clemizole hydrochloride blocks cardiac potassium currents stably expressed in HEK 293 cells. British journal of pharmacology, 174(3): 254-266. doi: 10.1111/bph.13679.

Juurlink DN (2020). Safety considerations with chloroquine, hydroxychloroquine and azithromycin in the management of SARS-CoV-2 infection. CMAJ : Canadian Medical Association journal = journal de l'Association medicale canadienne, 192(17): E450-E453. doi: 10.1503/cmaj.200528.

Kannankeril P, Roden DM \& Darbar D (2010). Drug-induced long QT syndrome. Pharmacological reviews, 62(4): 760-781. doi: 10.1124/pr.110.003723.

Kapplinger JD, Tester DJ, Salisbury BA, Carr JL, Harris-Kerr C, Pollevick GD, et al. (2009). Spectrum and prevalence of mutations from the first 2,500 consecutive unrelated patients referred for the FAMILION long QT syndrome genetic test. Heart Rhythm, 6(9): 1297-303. doi: 10.1016/j.hrthm.2009.05.021.

Kikuchi Y, Genka I, Ishizaki A, Sunagawa K, Yasuoka A \& Oka S (2002). Serious bradyarrhythmia that was possibly induced by lopinavir-ritonavir in 2 patients with acquired immunodeficiency syndrome. Clinical infectious diseases : an official publication of the Infectious Diseases Society of America, 35(4): 488-490. doi: $10.1086 / 341975$.

Kosmidis G, Veerman CC, Casini S, Verkerk AO, van de Pas S, Bellin M, et al. (2016). ReadthroughPromoting Drugs Gentamicin and PTC124 Fail to Rescue Nav1.5 Function of Human-Induced Pluripotent Stem Cell-Derived Cardiomyocytes Carrying Nonsense Mutations in the Sodium Channel Gene SCN5A. Circ Arrhythm Electrophysiol, 9(11): E4227. doi: 10.1161/circep.116.004227.

Kupferschmidt K \& Cohen J (2020). Race to find COVID-19 treatments accelerates. Science (New York, N.Y.), 367(6485): 1412-1413. doi: 10.1126/science.367.6485.1412. 
Kuryshev YA, Ficker E, Wang L, Hawryluk P, Dennis AT, Wible BA, et al. (2005). Pentamidine-induced long QT syndrome and block of hERG trafficking. The Journal of pharmacology and experimental therapeutics, 312(1): 316-323. doi:10.1124/jpet.104.073692.

Ledford H (2020). Chloroquine hype is derailing the search for coronavirus treatments. Nature. doi: 10.1038/d41586-020-01165-3.

Li K, Jiang Q, Bai X, Yang YF, Ruan MY \& Cai SQ (2017). Tetrameric assembly of $\mathrm{K}^{+}$channels requires ER-located chaperone proteins. Mol Cell, 65(1): 52-65. doi: 10.1016/j.molcel.2016.10.027.

Li P, Ninomiya H, Kurata Y, Kato M, Miake J, Yamamoto Y, et al. (2011). Reciprocal control of hERG stability by Hsp70 and Hsc70 with implication for restoration of LQT2 mutant stability. Circulation research, 108(4): 458-468. doi: 10.1161/CIRCRESAHA.110.227835.

Liu M, Shi G, Zhou A, Rupert CE, Coulombe KLK \& Dudley SC (2018). Activation of the unfolded protein response downregulates cardiac ion channels in human induced pluripotent stem cell-derived cardiomyocytes. Journal of molecular and cellular cardiology, 117: 62-71. doi: 10.1016/j.yjmcc.2018.02.011.

Liu Y, Xu X, Zhang Y, Li M, Guo J, Yan C, et al. (2020). Thioridazine Induces Cardiotoxicity via Reactive Oxygen Species-Mediated hERG Channel Deficiency and L-Type Calcium Channel Activation. Oxidative medicine and cellular longevity, 2020: 3690123. doi: 10.1155/2020/3690123.

Llanos-Cuentas A, Lacerda MV, Rueangweerayut R, Krudsood S, Gupta SK, Kochar SK, et al. (2014). Tafenoquine plus chloroquine for the treatment and relapse prevention of Plasmodium vivax malaria (DETECTIVE): a multicentre, double-blind, randomised, phase $2 \mathrm{~b}$ dose-selection study. Lancet (London, England), 383(9922): 1049-1058. doi: 10.1016/S0140-6736(13)62568-4.

Ma J, Guo L, Fiene SJ, Anson BD, Thomson JA, Kamp TJ, et al. (2011). High purity human-induced pluripotent stem cell-derived cardiomyocytes: electrophysiological properties of action potentials and ionic currents. Am J Physiol Heart Circ Physiol, 301(5): H2006-17. doi: 10.1152/ajpheart.00694.2011.

Massaeli H, Sun T, Li X, Shallow H, Wu J, Xu J, et al. (2010). Involvement of caveolin in low $\mathrm{K}^{+}$-induced endocytic degradation of cell-surface human ether-a-go-go-related gene (hERG) channels. The Journal of biological chemistry, 285(35): 27259-27264. doi: 10.1074/jbc.M110.124909.

Mehta A, Ramachandra CJA, Singh P, Chitre A, Lua CH, Mura M, et al. (2018). Identification of a targeted and testable antiarrhythmic therapy for long-QT syndrome type 2 using a patient-specific cellular model. Eur Heart J, 39(16): 1446-1455. doi: 10.1093/eurheartj/ehx394.

Mercuro NJ, Yen CF, Shim DJ, Maher TR, McCoy CM, Zimetbaum PJ, et al. (2020). Risk of QT Interval Prolongation Associated With Use of Hydroxychloroquine With or Without Concomitant Azithromycin Among Hospitalized Patients Testing Positive for Coronavirus Disease 2019 (COVID-19). JAMA Cardiol. doi:10.1001/jamacardio.2020.1834.

Milberg P, Eckardt L, Bruns HJ, Biertz J, Ramtin S, Reinsch N, et al. (2002). Divergent proarrhythmic potential of macrolide antibiotics despite similar QT prolongation: fast phase 3 repolarization prevents early afterdepolarizations and torsade de pointes. J Pharmacol Exp Ther, 303(1): 218-25. doi: 10.1124/jpet.102.037911.

Mitcheson JS, Chen J, Lin M, Culberson C \& Sanguinetti MC (2000). A structural basis for drug-induced long QT syndrome. Proc Natl Acad Sci U S A, 97(22): 12329-33. doi: 10.1073/pnas.210244497.

Mladěnka P, Applová L, Patočka J, Costa VM, Remiao F, Pourová J, et al. (2018). Comprehensive review of cardiovascular toxicity of drugs and related agents. Med Res Rev, 38(4): 1332-1403. doi: 10.1002/med.21476.

Moore N (2020). Chloroquine for COVID-19 Infection. Drug safety, 43(5): 393-394. doi: 10.1007/s40264-02000933-4.

Naksuk N, Lazar S \& Peeraphatdit TB (2020). Cardiac safety of off-label COVID-19 drug therapy: a review and proposed monitoring protocol. Eur Heart J Acute Cardiovasc Care: 2048872620922784. doi: 


\section{$10.1177 / 2048872620922784$.}

Nogawa H \& Kawai T (2014). hERG trafficking inhibition in drug-induced lethal cardiac arrhythmia. European journal of pharmacology, 741: 336-339. doi: 10.1016/j.ejphar.2014.06.044.

Nozaki Y, Honda Y, Tsujimoto S, Watanabe H, Kunimatsu T \& Funabashi H (2014). Availability of human induced pluripotent stem cell-derived cardiomyocytes in assessment of drug potential for QT prolongation. Toxicology and applied pharmacology, 278(1): 72-77. doi: 10.1016/j.taap.2014.04.007.

Ohtani H, Taninaka C, Hanada E, Kotaki H, Sato H, Sawada Y, et al. (2000). Comparative pharmacodynamic analysis of Q-T interval prolongation induced by the macrolides clarithromycin, roxithromycin, and azithromycin in rats. Antimicrobial agents and chemotherapy, 44(10): 2630-2637. doi: 10.1128/aac.44.10.26302637.2000.

Panel. C-TG. 2020. Coronavirus Diseases 2019 (COVID-19) Treatment Guidelines. National Institutes of Health. Available:https://www.covid19treatmentguidelines.nih.gov/[Accessed May 20, 2020].

Perrin MJ, Kuchel PW, Campbell TJ \& Vandenberg JI (2008). Drug binding to the inactivated state is necessary but not sufficient for high-affinity binding to human ether-à-go-go-related gene channels. Mol Pharmacol, 74(5): 1443-52. doi: 10.1124/mol.108.049056.

Portero V, Casini S, Hoekstra M, Verkerk AO, Mengarelli I, Belardinelli L, et al. (2017). Anti-arrhythmic potential of the late sodium current inhibitor GS-458967 in murine Scn5a-1798insD+/- and human SCN5A1795insD+/- iPSC-derived cardiomyocytes. Cardiovasc Res, 113(7): 829-838. doi:10.1093/cvr/cvx077.

Rajamani S, Eckhardt LL, Valdivia CR, Klemens CA, Gillman BM, Anderson CL, et al. (2006). Druginduced long QT syndrome: $\mathrm{hERG} \mathrm{K}^{+}$channel block and disruption of protein trafficking by fluoxetine and norfluoxetine. Br J Pharmacol, 149(5): 481-9. doi: 10.1038/sj.bjp.0706892.

Ray WA, Murray KT, Hall K, Arbogast PG \& Stein CM (2012). Azithromycin and the risk of cardiovascular death. The New England journal of medicine, 366(20): 1881-1890. doi: 10.1056/NEJMoa1003833.

Sala L, Gnecchi M \& Schwartz PJ (2019). Long QT Syndrome Modelling with Cardiomyocytes Derived from Human-induced Pluripotent Stem Cells. Arrhythm Electrophysiol Rev, 8(2): 105-110. doi: 10.15420/aer.2019.1.1.

Sala L, Yu Z, Ward-van Oostwaard D, van Veldhoven JP, Moretti A, Laugwitz KL, et al. (2016). A new hERG allosteric modulator rescues genetic and drug-induced long-QT syndrome phenotypes in cardiomyocytes from isogenic pairs of patient induced pluripotent stem cells. EMBO Mol Med, 8(9): 1065-81. doi: 10.15252/emmm.201606260.

Saleh M, Gabriels J, Chang D, Kim BS, Mansoor A, Mahmood E, et al. (2020). The Effect of Chloroquine, Hydroxychloroquine and Azithromycin on the Corrected QT Interval in Patients with SARS-CoV-2 Infection. Circulation. Arrhythmia and electrophysiology. doi: 10.1161/CIRCEP.120.008662.

Sănchez-Chapula JA, Ferrer T, Navarro-Polanco RA \& Sanguinetti MC (2003). Voltage-dependent profile of human ether-a-go-go-related gene channel block is influenced by a single residue in the S6 transmembrane domain. Molecular pharmacology, 63(5): 1051-1058. doi: 10.1124/mol.63.5.1051.

Sánchez-Chapula JA, Navarro-Polanco RA, Culberson C, Chen J \& Sanguinetti MC (2002). Molecular determinants of voltage-dependent human ether-a-go-go related gene (HERG) $\mathrm{K}^{+}$channel block. The Journal of biological chemistry, 277(26): 23587-23595. doi: 10.1074/jbc.M200448200.

Sánchez-Chapula JA, Salinas-Stefanon E, Torres-Jácome J, Benavides-Haro DE \& Navarro-Polanco RA (2001). Blockade of currents by the antimalarial drug chloroquine in feline ventricular myocytes. J Pharmacol Exp Ther, 297(1): 437-45.

Sapp JL, Alqarawi W, MacIntyre CJ, Tadros R, Steinberg C, Roberts JD, et al. (2020). Guidance On Minimizing Risk of Drug-Induced Ventricular Arrhythmia During Treatment of COVID-19: A Statement from 
the Canadian Heart Rhythm Society. The Canadian journal of cardiology. doi: 10.1016/j.cjca.2020.04.003.

Sarapa N, Nickens DJ, Raber SR, Reynolds RR \& Amantea MA (2008). Ritonavir 100 mg does not cause QTc prolongation in healthy subjects: a possible role as CYP3A inhibitor in thorough QTc studies. Clin Pharmacol Ther, 83(1): 153-9. doi: 10.1038/sj.clpt.6100263.

Saxena P, Zangerl-Plessl EM, Linder T, Windisch A, Hohaus A, Timin E, et al. (2016). New potential binding determinant for hERG channel inhibitors. Scientific reports, 6: 24182. doi: 10.1038/srep24182.

Schewe M, Sun H, Mert Ü, Mackenzie A, Pike ACW, Schulz F, et al. (2019). A pharmacological master key mechanism that unlocks the selectivity filter gate in K channels. Science (New York, N.Y.), 363(6429): 875-880. doi: $10.1126 /$ science.aav0569.

Schwartz PJ \& Ackerman MJ (2013). The long QT syndrome: a transatlantic clinical approach to diagnosis and therapy. Eur Heart J, 34(40): 3109-16. doi: 10.1093/eurheartj/eht089.

Schwartz PJ, Gnecchi M, Dagradi F, Castelletti S, Parati G, Spazzolini C, et al. (2019). From patientspecific induced pluripotent stem cells to clinical translation in long QT syndrome Type 2. Eur Heart J, 40(23): 1832-1836. doi: 10.1093/eurheartj/ehz023.

Schwartz PJ \& Woosley RL (2016). Predicting the Unpredictable: Drug-Induced QT Prolongation and Torsades de Pointes. Journal of the American College of Cardiology, 67(13): 1639-1650. doi: 10.1016/j.jacc.2015.12.063.

Shi YP, Thouta S \& Claydon TW (2020). Modulation of hERG K+ Channel Deactivation by Voltage Sensor Relaxation. Frontiers in pharmacology, 11: 139. doi: 10.3389/fphar.2020.00139.

Smith JL, Anderson CL, Burgess DE, Elayi CS, January CT \& Delisle BP (2016). Molecular pathogenesis of long QT syndrome type 2. J Arrhythm, 32(5): 373-380. doi: 10.1016/j.joa.2015.11.009.

Smith PL, Baukrowitz T \& Yellen G (1996). The inward rectification mechanism of the HERG cardiac potassium channel. Nature, 379(6568): 833-836. doi: 10.1038/379833a0.

Soliman EZ, Lundgren JD, Roediger MP, Duprez DA, Temesgen Z, Bickel M, et al. (2011). Boosted protease inhibitors and the electrocardiographic measures of QT and PR durations. Aids, 25(3): 367-77. doi: 10.1097/QAD.0b013e328341dcc0.

Spector PS, Curran ME, Zou A, Keating MT \& Sanguinetti MC (1996). Fast inactivation causes rectification of the IKr channel. The Journal of general physiology, 107(5): 611-619. doi: 10.1085/jgp.107.5.611.

Stas P, Faes D \& Noyens P (2008). Conduction disorder and QT prolongation secondary to long-term treatment with chloroquine. Int J Cardiol, 127(2): e80-2. doi: 10.1016/j.ijcard.2007.04.055.

Stower H (2020). Lopinavir-ritonavir in severe COVID-19. Nature medicine, 26(4): 465. doi: 10.1038/s41591020-0849-9.

Sun T, Guo J, Shallow H, Yang T, Xu J, Li W, et al. (2011). The role of monoubiquitination in endocytic degradation of human ether-a-go-go-related gene (hERG) channels under low $\mathrm{K}^{+}$conditions. The Journal of biological chemistry, 286(8): 6751-6759. doi: 10.1074/jbc.M110.198408.

Szekely Y, Lichter Y, Shrkihe BA, Bruck H, Oster HS \& Viskin S (2020). Chloroquine-induced torsade de pointes in a COVID-19 patient. Heart rhythm. doi: 10.1016/j.hrthm.2020.04.046.

Takemasa H, Nagatomo T, Abe H, Kawakami K, Igarashi T, Tsurugi T, et al. (2008). Coexistence of hERG current block and disruption of protein trafficking in ketoconazole-induced long QT syndrome. British journal of pharmacology, 153(3): 439-447. doi:10.1038/sj.bjp.0707537.

Tamargo J, Caballero R, Gómez R, Valenzuela C \& Delpón E (2004). Pharmacology of cardiac potassium channels. Cardiovasc Res, 62(1): 9-33. doi: 10.1016/j.cardiores.2003.12.026. 
Thomsen MB, Beekman JD, Attevelt NJ, Takahara A, Sugiyama A, Chiba K, et al. (2006). No proarrhythmic properties of the antibiotics Moxifloxacin or Azithromycin in anaesthetized dogs with chronic-AV block. Br J Pharmacol, 149(8): 1039-48. doi: 10.1038/sj.bjp.0706900.

Traebert M, Dumotier B, Meister L, Hoffmann P, Dominguez-Estevez M \& Suter W (2004). Inhibition of hERG K ${ }^{+}$currents by antimalarial drugs in stably transfected HEK293 cells. Eur J Pharmacol, 484(1): 41-8. doi: 10.1016/j.ejphar.2003.11.003.

van Noord C, Eijgelsheim M \& Stricker BHC (2010). Drug- and non-drug-associated QT interval prolongation. British journal of clinical pharmacology, 70(1): 16-23. doi: 10.1111/j.1365-2125.2010.03660.x.

Vandenberg JI, Perozo E \& Allen TW (2017). Towards a Structural View of Drug Binding to hERG K+ Channels. Trends in pharmacological sciences, 38(10): 899-907. doi: 10.1016/j.tips.2017.06.004.

Vandenberg JI, Perry MD, Perrin MJ, Mann SA, Ke Y \& Hill AP (2012). hERG K+ channels: structure, function, and clinical significance. Physiological reviews, 92(3): 1393-1478. doi: 10.1152/physrev.00036.2011.

Veerman CC, Kosmidis G, Mummery CL, Casini S, Verkerk AO \& Bellin M (2015). Immaturity of human stem-cell-derived cardiomyocytes in culture: fatal flaw or soluble problem? Stem Cells Dev, 24(9): 1035-52. doi: $10.1089 / \mathrm{scd} .2014 .0533$.

Vicente J, Zusterzeel R, Johannesen L, Ochoa-Jimenez R, Mason JW, Sanabria C, et al. (2019). Assessment of Multi-Ion Channel Block in a Phase I Randomized Study Design: Results of the CiPA Phase I ECG Biomarker Validation Study. Clinical pharmacology and therapeutics, 105(4): 943-953. doi: 10.1002/cpt.1303.

Volberg WA, Koci BJ, Su W, Lin J \& Zhou J (2002). Blockade of human cardiac potassium channel human ether-a-go-go-related gene (HERG) by macrolide antibiotics. The Journal of pharmacology and experimental therapeutics, 302(1): 320-327. doi: 10.1124/jpet.302.1.320.

Walker VE, Wong MJ, Atanasiu R, Hantouche C, Young JC \& Shrier A (2010). Hsp40 chaperones promote degradation of the HERG potassium channel. J Biol Chem, 285(5): 3319-29. doi: 10.1074/jbc.M109.024000.

Wang DT, Hill AP, Mann SA, Tan PS \& Vandenberg JI (2011). Mapping the sequence of conformational changes underlying selectivity filter gating in the $\mathrm{K}_{\mathrm{V}} 11.1$ potassium channel. Nature structural \& molecular biology, 18(1): 35-41. doi: 10.1038/nsmb.1966.

Wang L, Wible BA, Wan X \& Ficker E (2007). Cardiac glycosides as novel inhibitors of human ether-ago-go-related gene channel trafficking. The Journal of pharmacology and experimental therapeutics, 320(2): 525-534. doi: 10.1124/jpet.106.113043.

Wang M, Cao R, Zhang L, Yang X, Liu J, Xu M, et al. (2020). Remdesivir and chloroquine effectively inhibit the recently emerged novel coronavirus (2019-nCoV) in vitro. Cell research, 30(3): 269-271. doi: 10.1038/s41422-020-0282-0.

Wang Q, Groenendyk J \& Michalak M (2015). Glycoprotein Quality Control and Endoplasmic Reticulum Stress. Molecules (Basel, Switzerland), 20(8): 13689-13704. doi: 10.3390/molecules200813689.

Wang W \& MacKinnon R (2017). Cryo-EM Structure of the Open Human Ether-à-go-go-Related K ${ }^{+}$Channel hERG. Cell, 169(3): 422-430.e10. doi: 10.1016/j.cell.2017.03.048.

Warmke JW \& Ganetzky B (1994). A family of potassium channel genes related to eag in Drosophila and mammals. Proceedings of the National Academy of Sciences of the United States of America, 91(8): 34383442. doi: $10.1073 /$ pnas.91.8.3438.

Whicher JR \& MacKinnon R (2016). Structure of the voltage-gated K+ channel Eag1 reveals an alternative voltage sensing mechanism. Science (New York, N.Y.), 353(6300): 664-669. doi: 10.1126/science.aaf8070.

White NJ (2007). Cardiotoxicity of antimalarial drugs. The Lancet. Infectious diseases, 7(8): 549-558. doi: 10.1016/S1473-3099(07)70187-1. 
Wible BA, Hawryluk P, Ficker E, Kuryshev YA, Kirsch G \& Brown AM (2005). HERG-Lite: a novel comprehensive high-throughput screen for drug-induced hERG risk. J Pharmacol Toxicol Methods, 52(1): 136-45. doi: 10.1016/j.vascn.2005.03.008.

Witchel HJ, Hancox JCJC, Pharmacology E \& Physiology (2001). Familial And Acquired Long QT Syndrome And The Cardiac Rapid Delayed Rectifier Potassium Current. 27(10): 753-766. doi: 10.1046/j.14401681.2000.03337.x.

Wu C-I, Postema PG, Arbelo E, Behr ER, Bezzina CR, Napolitano C, et al. (2020). SARS-CoV-2, COVID19 and inherited arrhythmia syndromes. Heart rhythm. doi: 10.1016/j.hrthm.2020.03.024.

Wu X, Sun L, Zha W, Studer E, Gurley E, Chen L, et al. (2010). HIV protease inhibitors induce endoplasmic reticulum stress and disrupt barrier integrity in intestinal epithelial cells. Gastroenterology, 138(1): 197-209. doi: $10.1053 /$ j.gastro.2009.08.054.

Wuriyanghai Y, Makiyama T, Sasaki K, Kamakura T, Yamamoto Y, Hayano M, et al. (2018). Complex aberrant splicing in the induced pluripotent stem cell-derived cardiomyocytes from a patient with long QT syndrome carrying KCNQ1-A344Aspl mutation. Heart Rhythm, 15(10): 1566-1574. doi: 10.1016/j.hrthm.2018.05.028.

Yang Z, Prinsen JK, Bersell KR, Shen W, Yermalitskaya L, Sidorova T, et al. (2017). Azithromycin Causes a Novel Proarrhythmic Syndrome. Circulation. Arrhythmia and electrophysiology, 10(4). doi: 10.1161/CIRCEP.115.003560.

Yao X, Ye F, Zhang M, Cui C, Huang B, Niu P, et al. (2020). In Vitro Antiviral Activity and Projection of Optimized Dosing Design of Hydroxychloroquine for the Treatment of Severe Acute Respiratory Syndrome Coronavirus 2 (SARS-CoV-2). Clinical infectious diseases : an official publication of the Infectious Diseases Society of America. doi: 10.1093/cid/ciaa237.

Yazdany J \& Kim AHJ (2020). Use of Hydroxychloroquine and Chloroquine During the COVID-19 Pandemic: What Every Clinician Should Know. Ann Intern Med. doi: 10.7326/m20-1334.

Zhang KP, Yang BF \& Li BX (2014). Translational toxicology and rescue strategies of the hERG channel dysfunction: biochemical and molecular mechanistic aspects. Acta Pharmacol Sin, 35(12): 1473-84. doi: 10.1038/aps.2014.101.

Zhang M, Xie M, Li S, Gao Y, Xue S, Huang H, et al. (2017). Electrophysiologic Studies on the Risks and Potential Mechanism Underlying the Proarrhythmic Nature of Azithromycin. Cardiovascular toxicology, 17(4): 434-440. doi: 10.1007/s12012-017-9401-7.

Zheng Y-Y, Ma Y-T, Zhang J-Y \& Xie X (2020). COVID-19 and the cardiovascular system. Nature reviews. Cardiology, 17(5): 259-260. doi: 10.1038/s41569-020-0360-5.

Zhi D, Feng P-F, Sun J-L, Guo F, Zhang R, Zhao X, et al. (2015). The enhancement of cardiac toxicity by concomitant administration of Berberine and macrolides. European journal of pharmaceutical sciences : official journal of the European Federation for Pharmaceutical Sciences, 76: 149-155. doi: 10.1016/j.ejps.2015.05.009.

Zhou S, Yung Chan S, Cher Goh B, Chan E, Duan W, Huang M, et al. (2005). Mechanism-based inhibition of cytochrome P450 3A4 by therapeutic drugs. Clinical pharmacokinetics, 44(3): 279-304. doi: 10.2165/00003088-200544030-00005.

Table 1. Potential therapeutic drugs for COVID-19 and their adverse effect of prolonged QT interval. 


\begin{tabular}{|c|c|c|c|c|}
\hline Drug name & $\begin{array}{l}\text { Effects on } \\
\text { COVID-19 }\end{array}$ & $\begin{array}{l}\text { Assessments of } \\
\text { QT interval }\end{array}$ & $\begin{array}{l}\text { Mechanisms on } \\
\text { hERG }\end{array}$ & References \\
\hline $\begin{array}{l}\text { Chloroquine } \\
\text { Hydroxychloroquine }\end{array}$ & $\begin{array}{l}\text { Reduced viral load } \\
\text { and inhibition of } \\
\text { SARS-CoV-2 in } \\
\text { vitro. }\end{array}$ & $\begin{array}{l}\mathrm{QT} \text { prolongation } \\
\text { resulting in } \mathrm{TdP} \text {. }\end{array}$ & $\begin{array}{l}\text { Blocking } \mathrm{I}_{\mathrm{Kr}} \\
\text { current. Slowed rate } \\
\text { of deactivation and } \\
\text { increased transport } \\
\text { of hERG by } \\
\text { chloroquine. }\end{array}$ & $\begin{array}{l}\text { (Borsini et al. 2012, } \\
\text { Gautret et al. 2020, } \\
\text { Saleh et al. 2020, } \\
\text { Sánchez-Chapula et } \\
\text { al. } 2002 \text {, } \\
\text { Sánchez-Chapula et } \\
\text { al. 2001, Yao et al. } \\
\text { 2020) }\end{array}$ \\
\hline Azithromycin & $\begin{array}{l}\text { Enhanced } \\
\text { Hydroxychloroquine } \\
\text { potency of viral } \\
\text { elimination. }\end{array}$ & $\begin{array}{l}\text { QT prolongation } \\
\text { and increased risk of } \\
\text { TdP in combination } \\
\text { with Chloroquine or } \\
\text { hydroxychloroquine. }\end{array}$ & $\begin{array}{l}\text { Blocking } I_{\mathrm{Kr}} \text { under } \\
\text { high plasma } \\
\text { concentration. No } \\
\text { evidence of } \\
\text { interference with } \\
\text { hERG trafficking. }\end{array}$ & $\begin{array}{l}\text { (Chorin et al. } 2020 \text {, } \\
\text { Gautret et al. 2020, } \\
\text { Juurlink 2020, Yang } \\
\text { et al. 2017, Zhang } \\
\text { et al. 2017) }\end{array}$ \\
\hline Lopinavir/ritonavir & $\begin{array}{l}\text { Reduced length of } \\
\text { hospital stay for } \\
\text { severe patients. }\end{array}$ & $\begin{array}{l}\text { Potential QT } \\
\text { prolongation. }\end{array}$ & $\begin{array}{l}\text { hERG channel } \\
\text { blockade. No } \\
\text { evidence of } \\
\text { interference with } \\
\text { hERG trafficking. }\end{array}$ & $\begin{array}{l}\text { (Anson et al. 2005, } \\
\text { Cao et al. 2020a) }\end{array}$ \\
\hline
\end{tabular}

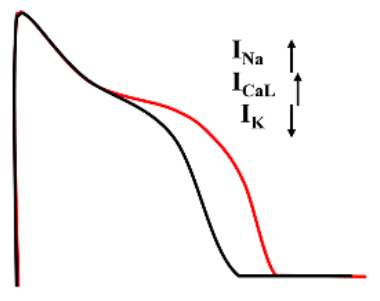

a

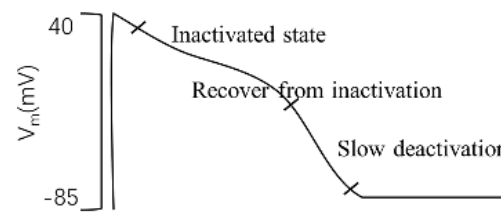

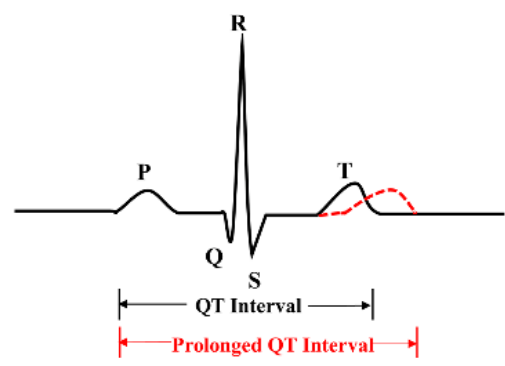

b

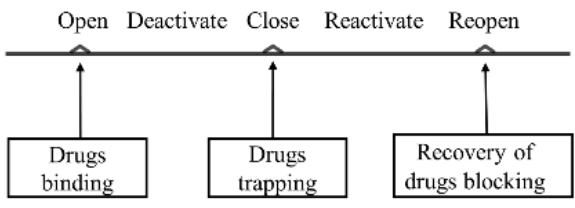

Fig 1. A prolonged action potential duration by increased inward current and weakened outward currents (a ) and manifested on ECG (b ). In the early stage of the action potential, the hERG channel experiences a short activation but rapidly inactivates. As depolarization voltage continues to decrease, the hERG reactivates, and then the deactivation rate is much slower to generate the tail currents(c $)$. hERG channel opens, with drugs entering the cavity and binding, then the channel closes and the drug is trapped in the cavity. When the channel reopens, the drug blocking effect is released (d ). 


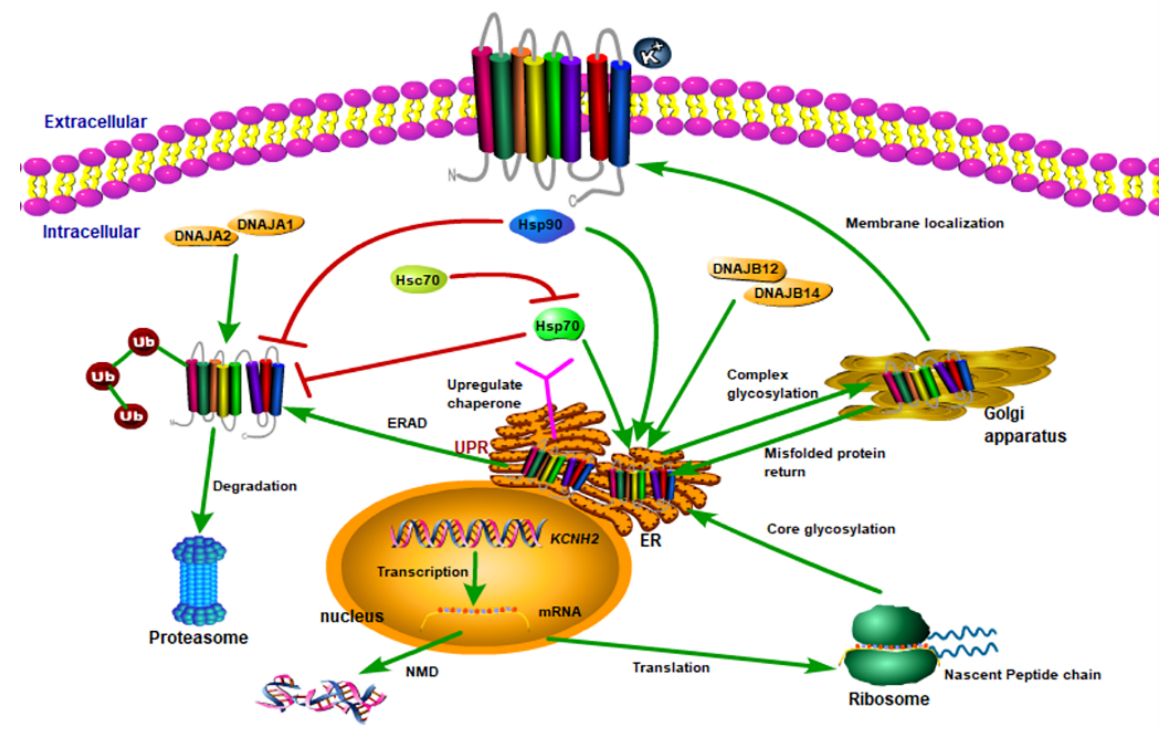

Fig 2. hERG biogenesis and quality control. The KCNH2gene is transcribed in the nucleus to generate mRNA. The unqualified mRNA undergoes nonsense-mediated mRNA decay (NMD). The qualified mRNA is translated in the ribosome and is transported to the endoplasmic reticulum (ER) for initial glycosylation. Correctly folded proteins are transported to the plasma membrane to function and misfolded proteins return to the ER to upregulate molecular chaperone levels, including Hsp70, Hsp90, and Hsp40 to regulate protein maturation and degradation (green arrows indicate promotion, the red arrow indicates inhibition). If the misfolded protein persists, it will trigger the unfolded protein response (UPR) making protein enters the ER-associated degradation (ERAD).

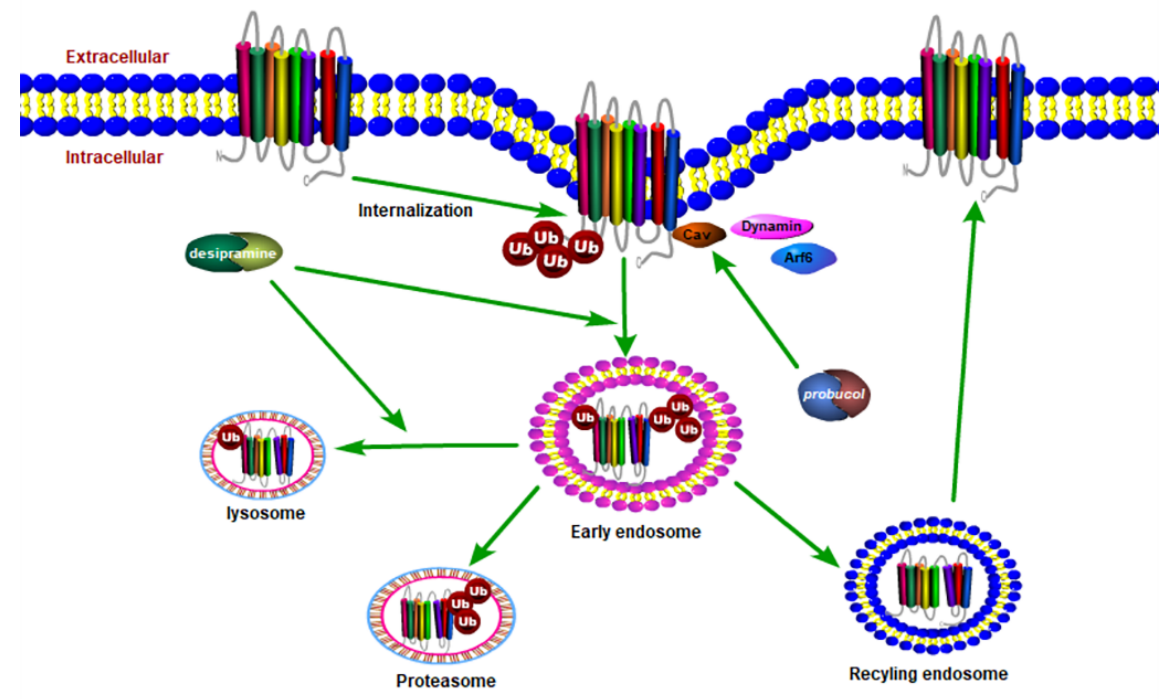


Fig 3. hERG internalization and recycling. hERG channel on the membrane will internalize into clathrin-coated vesicles upon ubiquitination. Caveolin (Cav), dynamin, and Arf6 regulate protein internalization and internalized proteins are degraded by lysosomes or proteasomes, or recycled back to the membrane. Probucol accelerating Cav1 turnover promoting hERG internalization. Desipramine increases channel endocytosis and ubiquitination degradation by the lysosome.

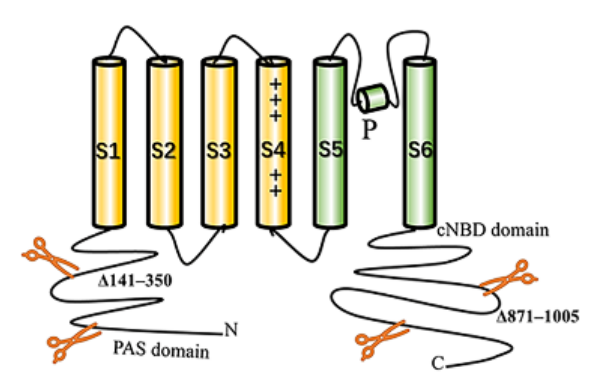

a

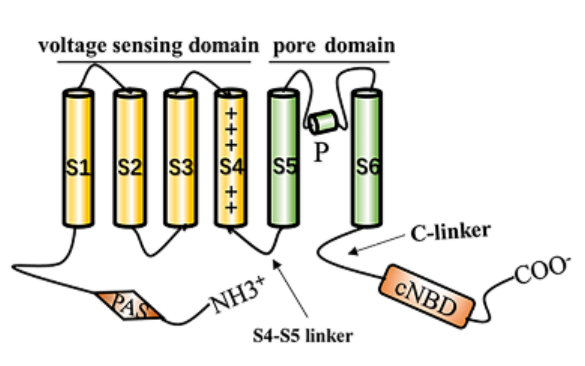

$\mathrm{b}$

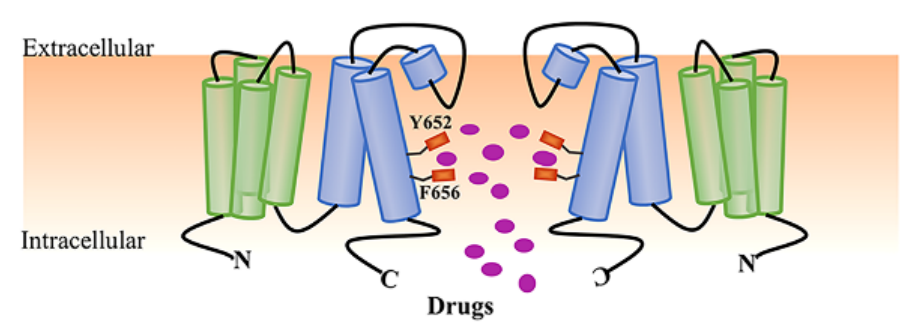

c

Fig 4. hERG channel structures and drug binding sites. The cryo-EM structure of hERG deleted most of the expected unstructured cytoplasmic regions ( $\Delta 141-350$ at the N-terminal and $\Delta 871-1005$ at the C-terminal) (a ) and hERG (Kv11.1) channel containing six transmembrane fragments (S1 -S6), the Nterminal Per-Arnt-Sim (PAS) domain, and the C-terminal cyclic nucleotide-binding domain (cNBD). S1-S4 act as transmembrane voltage sensing (VSD) with charged residues and S5-S6 form the pore domain (b ). hERG channel opens and drugs enter the central cavity. Y652 and F656 on the S6 are two key drug binding sites (c).

Competing Interests' Statement: none. 